\title{
Addison's disease presenting as anorexia nervosa in a
} young man

\author{
M.V. Tobin and A.I. Morris \\ Gastroenterology Unit, Royal Liverpool Hospital, Liverpool L7 8XP, UK.
}

\begin{abstract}
Summary: A young man with a long history of obsessional traits and food fads presented with anorexia, vomiting and marked weight loss. He showed little concern for his physical state and his vomiting was frequently witnessed as self-induced. A diagnosis of anorexia nervosa was made and he took his own discharge from hospital. He was readmitted one month later, severely cachectic and with biochemical abnormalities consistent with advanced Addison's disease which was subsequently confirmed. He responded dramatically, both mentally and physically, to corticosteroid therapy. It is likely that anorexia nervosa, relatively rare in males, was a manifestation of the psychological abnormalities commonly seen in severe Addison's disease.
\end{abstract}

\section{Introduction}

Psychological changes are common in Addison's disease and frank psychosis is well recognized. ${ }^{1}$ Anorexia nervosa, predominantly a disease of young women, ${ }^{2}$ has never been reported in association with Addison's disease. We report a case of anorexia nervosa, apparently precipitated by acute adrenal insufficiency, in a young man with a long history of minor psychological disturbances and its complete remission following corticosteroid replacement for Addison's disease.

\section{Case report}

A 20 year old vegan was admitted to hospital following a visit from his general practitioner at the request of his parents. They were concerned about their son's recent weight loss, his depressed and apathetic mood, loss of appetite and intermittent vomiting. He had lost approximately $18 \mathrm{~kg}$ in weight in the previous 6 months and had refused to seek medical help. He had strictly adhered to a vegetarian diet for the past two years and had numerous food fads since the age of 10 years. He was seen by a psychologist at that time because of a refusal to take food, at which stage he was showing 'minor psychological disturbances including abnormal obsessional traits'.

Correspondence: M.V. Tobin, M.B., M.R.C.P., Department of Medicine, University of Manchester, Hope Hospital, Salford M6 8HD, UK.

Accepted: 7 June 1988
He admitted to recent depression with insomnia and lack of concentration which he attributed to social isolation because of chronic unemployment. Sexual interest and potency had declined and he insisted that he was taking adequate nutrition, denying that he was underweight.

On examination, he was malnourished and dehydrated, weighing $40 \mathrm{~kg}$ (body mass index 14.3). He was not pigmented and blood pressure was $90 / 60 \mathrm{mmHg}$. Serum sodium was $126 \mathrm{mmol} / 1$, potassium $3.8 \mathrm{mmol} / \mathrm{l}$, urea $6.4 \mathrm{mmol} / \mathrm{l}$ and glucose $4.7 \mathrm{mmol} / \mathrm{l}$.

While in hospital he refused all food, only taking water. $\mathrm{He}$ had episodic vomiting which was frequently witnessed as self-induced and the vomit was sometimes concealed. On formal psychiatric assessment he was considered to have classical anorexia nervosa with a typical premorbid personality. He refused further investigation and treatment and took his own discharge against medical advice. One month later, he was readmitted severely dehydrated and cachectic and now weighing only $38.5 \mathrm{~kg}$. Serum sodium had fallen to $114 \mathrm{mmol} / \mathrm{l}$, potassium was $5.0 \mathrm{mmol} / 1$, urea $31.0 \mathrm{mmol} / \mathrm{l}$ and glucose $5.4 \mathrm{mmol} / \mathrm{l}$. Other investigations were as follows: $09.00 \mathrm{~h}$ cortisol $124 \mathrm{nmol} / 1$ (normal $130-690 \mathrm{nmol} / \mathrm{l}$ ) with no response to $1 \mathrm{mg}$ of tetracosactrin, ACTH $1687 \mathrm{ng} / 1$ (normal 10-80); adrenal antibodies, Mantoux test 1:1000, sputum, urine and bone marrow aspirate for acid-fast bacilli all negative, chest and abdominal X-rays normal.

$\mathrm{He}$ was commenced on hydrocortisone $20 \mathrm{mg}$ in the morning and $10 \mathrm{mg}$ in the afternoon with 
fludrocortisone $100 \mu \mathrm{g}$ and he made a spectacular recovery, eating normally and gaining $12 \mathrm{~kg}$ in weight in the following two months. His mental state, likewise, returned to normal, showing interest in his treatment and securing employment within a short period of time.

Three years later, he remains entirely well. His obsessive personality persists but his eating behaviour is normal. He accepts his present weight of approximately $64 \mathrm{~kg}$ as his ideal body weight.

\section{Discussion}

Although in his original description of the disease in $1855^{3}$ Addison referred to the frequency of psychological abnormalities in his 11 patients, it was not until 1942 that the occurrence of abnormal mental states was first clearly described. ${ }^{1}$ In 1953 , the first definitive comparative psychiatric appraisal of the mental state of patients with Addison's disease was published in which three categories of psychiatric disturbance were described. ${ }^{4}$ The first was an acute organic reaction characterized by delirium and recognized as a feature of acute or terminal adrenal insufficiency. The second and third, chronic mood abnormalities and psychoses, were found only in chronic adrenal insufficiency. It is now known that psychological changes are found in almost all patients with severe Addison's disease 5.6 and frank psychosis is well recognized..$^{7-9}$ Many cases of acute psychotic reactions, usually of a paranoid schizophrenic nature, ${ }^{10}$ or severe conversion disorders, ${ }^{11}$ usually responding to replacement corticosteroid therapy, have been reported. More recently, chronic self-mutilation in a 14 year old girl that regressed completely following treatment for previously unsuspected Addison's disease has been described. ${ }^{12}$

In man, raised circulating $\beta$-endorphins occur in association with raised ACTH levels ${ }^{13}$ suggesting a possible explanation for the observed psychological changes since $\beta$-endorphin administration is known to produce a neuroleptic-like syndrome in rats. ${ }^{14}$

Almost invariably anorexia nervosa is associated with hypercortisolism ${ }^{15}$ due to reduced metabolic clearance of cortisol, and basal plasma ACTH is normal. Nevertheless we cannot entirely discount the possibility that adrenal failure was a consequence of chronic, severe malnutrition in our patient. However, the primacy of Addison's disease as the basis for anorexia nervosa is suggested by the rapid improvement in mental state following corticosteroid administration. Although spontaneous remission in anorexia nervosa is sometimes prompted by a near-death experience, we feel that this sequence of events is most unlikely in our patient because of his sustained well-being 3 years later. It is likely that the onset of Addison's disease precipitated the psychological and somatic manifestations of anorexia nervosa. Although vomiting and weight loss frequently occur in untreated chronic adrenal insufficiency, ${ }^{16}$ and indeed our patient's cachectic state may have been partly attributable to this, nevertheless, he displayed the classical features of anorexia nervosa at presentation, fulfilling the DSM-III diagnostic criteria for this condition. ${ }^{17}$

Anorexia nervosa is relatively rare in males, accounting for approximately $10 \%$ of new cases. ${ }^{18}$ Its occurrence may indicate underlying Addison's disease which should be excluded in all cases.

\section{References}

1. Engel, G.L. \& Margolin, S.G. Neuropsychiatric disturbances in internal disease: metabolic factors and electroencephalographic correlations. Arch Int Med 1942, 70: 236.

2. Bruch, H. Anorexia nervosa and its differential diagnosis. J Nerv Ment Dis 1966, 141: 555.

3. Addison, T. On the Constitutional and Local Effects of Disease of the Suprarenal Capsules. D. Highley, London, 1855.

4. Stoll, W.A. Die Psychiatrie Des Morbus Addison. Thieme Verlag, Stuttgart, 1953.

5. Cleghorn, R.A. Adrenal cortical insufficiency: Psychological and neurological observations. Can Med Assoc $J$ 1951, 65: 449-454.

6. Sorkin, S.A. Addison's disease. Medicine 1949, 28: $371-425$.

7. Lever, E.G. \& Stansfield, S.A. Addison's disease, psychosis, and the syndrome of inappropriate secretion of antidiuretic hormone. $B r J$ Psychiatry 1983, 143: 406-410.

8. Cohen, S.L. \& Marks, I.M. Prolonged organic psychosis with recovery in Addison's disease. $J$ Neurol Neurosurg Psychiatry 1961, 24: 366-368.

9. McCulloch, T.A.H. \& Calverley, M.O. Addison's disease with psychosis. Can Med Assoc J 1961, 85: 31-33.

10. Mattson, B. Addison's disease and psychosis. Acta Psychiatr Scand 1974; (Suppl 255): 203-210.

11. Demilio, L., Dackis, C.A., Gold, M.S. \& Ehrenkranz, J.R. Addison's disease initially diagnosed as bereavement and conversion disorder. Am J Psychiatr 1984, 141: 1647-1648. 
12. Rajathurai, A., Chazan, B.I. \& Jeans, J.E. Self mutilation as a feature of Addison's disease. $\mathrm{Br}$ Med $\mathrm{J}$ 1983, 287: 1027.

13. Mullen, P.E., Jeffcoate, W.J., Linsell, C., Howard, R. \& Rees, L.H. The circadian variation of immunoreactive lipotrophin and its relationship to ACTH and growth hormone in man. Clin Endocrinol 1979, 11: 533-539.

14. Jacquet, Y.F. \& Marks, N. The C-fragment of Blipotrophin: an endogenous neuroleptic or antipsychotogen? Science 1976, 194: 632-635.

15. Gold, P.W., Gwirtzman, H., Augerinos, P.C. et al. Abnormal hypothalamic-pituitary-adrenal function in anorexia nervosa. Pathophysiologic mechanisms in underweight and weight-corrected patients. $N$ Engl $J$ Med 1986, 314: 1335-1342.
16. Nerup, J. Addison's disease - clinical studies. A report of 108 cases. Acta Endocrinol 1974, 76: 127-141.

17. American Psychiatric Association. Diagnostic and Statistical Manual of Mental Disorders, 3rd edition. American Psychiatric Association, Washington, DC, 1980.

18. Williams, P. \& King, M. The 'epidemic' of anorexia nervosa: another medical myth? Lancet 1987, i: 205-207. 